\title{
Use of Virtual Reality in Participatory Design
}

\author{
Mauricio Loyola ${ }^{1}$, Bruno Rossi ${ }^{2}$, Constanza Montiel ${ }^{3}$, Max Daiber $^{4}$ \\ 1,2,3,4 Universidad de Chile, Santiago, Chile \\ Imloyola@uchile.cl²brossi@uchilefau.cl \\ 3maria.montiel@ug.uchile.cl
}

Virtual Reality technology was used as a visualization tool in a participatory design process of an urban design project in Santiago, Chile. Community members with little or no familiarity with digital technologies visualized the project using traditional means of architectural representation and immersive virtual reality, and then, answered standardized questionnaires on spatial comprehension. Participants who visualized the project using virtual reality showed a higher level of spatial comprehension and a more precise understanding of the formal and spatial qualities of the project than users who used traditional means.

Keywords: Virtual Reality, Participatory Design, Urban Design, Head Mounted Displays

\section{INTRODUCTION}

Studies show that participatory design methods help architects and urban designers to develop projects that respond better to the requirements and aspirations of users (Fernández, 2015; Cámara 2012; MINVU, 2010; Luck, 2007; Crewe 2001). However, for a participatory design process to be beneficial and effective in improving designs, a fundamental condition must be met: participants must understand the physical and spatial qualities of the projects to a point where they can provide relevant comments that are applicable and informative to the design.

The traditional means of architectural representation usually employed in these processes seem to be not effective when used by people who are not familiar with them. Technical drawings are difficult to understand for the non-specialized public. Tridimensional models and images are useful for understanding the general appearance of a project, but they do not communicate the spatial properties of the de- sign, such as aspects of size, scale, configuration, of spatial connectivity. Many times, these are precisely the aspects that professional teams want to analyze when they carry out participatory design processes.

Several authors have claimed that immersive virtual reality (VR) technologies, and particularly Head Mounted Displays (HMDs), may contribute to solve this problem. The natural sense of presence that is achieved with immersive HMDs generates a spatial perception similar to the actual experience in the physical space, allowing for a more reliable, in-depth, and intuitive understanding of space (Kuliga et al., 2015; Portman et al., 2015; Kalisperis et al., 2006). In academic settings, HMDs have been tested in architectural studios for simulating spatial perception for almost a decade, with generally positive results (Milovanvic et al., 2017; Hermund and Klint, 2016; Kreutzberg, 2014; Angulo and Vasquez de Velasco, 2013; Abdelhameed, 2013; Bruder et al., 2010). The popularization of several commercial HMDs (Oculus 
Rift, HTC Vive, HP Reverb, and others) have sparked a growing interest in exploring the use of these intuitive devices to communicate architectural ideas (Ghani et al., 2016; Kreutberg 2015; 2016).

A promising but still little studied niche of application is the use of VR HMD technologies in participatory design processes of public urban and architectural projects. There are previous studies on VR in participatory design processes, but they refer to other VR technologies (e.g., CAVE systems,desktopbased virtual environments), or are focused on other types of projects (e.g. interior design, product design) (Eisapour et al., 2018; Bakr et al., 2018; Hayek et al., 2016; Thalen and der Voort, 2012; Bruno and Muzzupappa, 2010; Drettakis et al., 2006). Public urban projects face particular challenges that make the methods and results from previous studies not directly transferable. Many times the projects take place in communities where participants have low educational levels and experience more difficulties in understanding technical information. Their familiarity with digital technologies may be significantly lower than other populations typically addressed in similar VR studies (e.g., architecture students, AEC professionals), and the risks associated with immersive VR (e.g., dizziness, visual discomfort) are therefore higher. Public participation processes usually involve dozens, if not hundreds, of persons that need to visualize and understand the projects in a short period, which represents a major logistical issue for a technology that requires to be used individually.

This study aims to propose a methodology for the practical application of HMD VR technologies in participatory design processes for public projects. A previous study by the authors tested the technology in a controlled experiment with a small sample (Montiel and Loyola, 2016). This paper presents the next phase of the research: the application of the technology in an actual urban design project and the assessment of the experience using standardized instruments with a larger sample of participants.

\section{METHODS}

The case study was the urban design project "Parque Articulador" in Villa Alessandri, Pedro Aguirre Cerda, Santiago, Chile. The project proposed the transformation of unused open space into a public park with new pavements, vegetation, playgrounds, seating areas, and lighting. Sensitive aspects of the design included new pedestrian paths connecting with surrounding public housing and the location of the new playgrounds and benches. Several characteristics made this project particularly convenient as a case study: limited size, high urban impact, low educational level of participants, and advanced stage of the design development.

The design of the project and the participatory design process were led by professionals from the Ministry of Housing and Urban Planning of Chile, following standard protocols for public projects. The role of the research team was limited to the application and assessment of VR technologies.

First, the researchers attended a series of coordination meetings with the government designers and participatory design experts, made reconnaissance site visits, and attended preliminary participatory meetings with the community to familiarize with the participatory protocols and details of the project.

Then, the research team built a virtual reality project model. The geometric model was built using Autodesk 3ds Max using the information provided by the designers. The texturing was done using a photographic survey conducted by the researchers. The VR scenario and navigation path were defined using Unreal Engine. The RV experience was structured based on a predetermined fixed navigation route where the user was free to move his/her head and torso but not to walk. This particularly navigation setup was chosen to prevent visual discomfort and dizziness in participants not familiar with VR technologies. For the visualization, two Oculus Rift CV1 devices were used. The VR model was reviewed by the government architects and urban designers to validate its fidelity with the proposed project. 
Figure 1

Virtual model of the Parque Articulador project, Villa

Alessandri, Pedro

Aguirre Cerda, Santiago, Chile.
Figure 2

Community members visualized the project using Oculus Rift CV1 devices

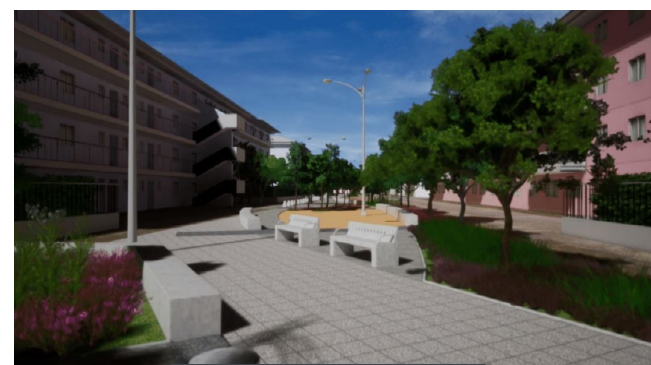

The experimental activity consisted of a session with the community to show them the project and to receive comments. The VR model was presented in parallel with the traditional methods used in participatory design processes (technical drawings and 3D images developed by the designers) in order to have a comparable control case. A random group of participants was asked to visualize and examine the design project using traditional methods and then to answer a spatial comprehension questionnaire. Then, the participants were asked to visualize the VR model and answer a similar questionnaire, which also includes background questions to know their level of familiarity with VR and digital technologies. All participants were also interviewed before and after each visualization, and all their spontaneous comments during the visualization were recorded. Additionally, their sense of presence in the VR experience was analyzed using the 18 factors proposed by Witmer and Singer (1998) as theoretical framework.

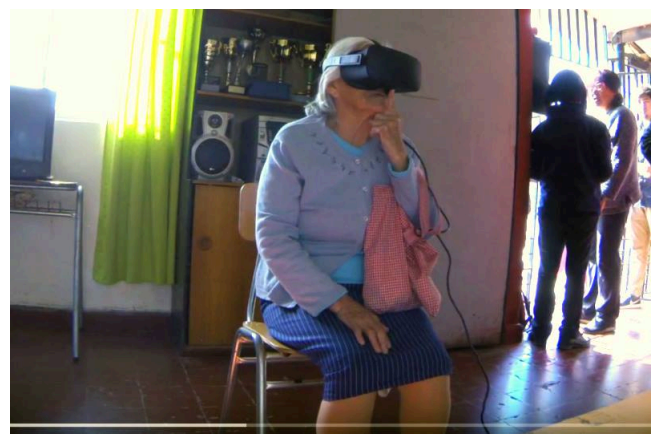

\section{RESULTS}

In general, the results of this experimental experience support the hypothesis that VR is an effective tool for the representation of urban design projects in participatory design processes with participants not familiar with the technology.

The preliminary analysis of the structured questionnaires and spontaneous comments during the visualization experience suggest that participants who visualized the project with the VR model showed a higher level of spatial comprehension and a more precise understanding of the characteristics of the project than those who examined it using only technical drawings and 3D images. For example, participants could easily identify the different zones in the park (e.g., children area, walking area, open plaza) and describe their differences in pavement type or vegetation density. They could also give specifics about color, quantity, and size of the benches and playground equipment. On the other hand, participants that visualized the project using traditional means could not distinguish zones nor identify particular elements.

One of the most apparent differences between the two groups was the level of understanding of the location of the architectural elements within the park and in relation to the surrounding context. While participants who used VR had no problem locating specific elements, participants who used traditional means struggled to associate 3D images with their location on the 2D plan drawings. Participants who used VR also showed greater confidence in their responses than participants who used traditional means, who, at times, seemed to be guessing. These findings seem to suggest that the use of VR technologies allows a better and more accurate generation of mental maps of design projects than traditional media based on isolated renderings and architectural plan views.

The qualitative analysis of the Witmer-Singer factors (Table 1) shows that Realism Factors were developed adequately in the virtual environment (VE), but Control, Sensory and Distraction Factors were ad- 


\begin{tabular}{llll}
\hline Control Factors & Sensory Factors & Distraction Factors & Realism Factors \\
\hline - Degree of control & - Sensory modality & - Isolation & - Scene realism \\
- Immediacy of control & - Environmental richness & - Selective attention & - Information consistency with \\
- Anticipation of events & - Multimodal presentation & - Interface awareness & - Meaningfulness of experience \\
- Mode of control & - Consistency of multimodal & & - Separation anxiety \\
- Physical environment & information & & \\
modifiability & - Degree of movement & & \\
& - Active search & & \\
& - Acreption &
\end{tabular}

Table 1

Factors affecting

the sense of

presence. Source:

Witmer and Singer

(1998). versely affected by the research design and experimental setup.

Control Factors were intentionally limited in this pilot case because of methodological or safety reasons. The degree of control (over the task environment or in interacting with the VE) and the physical environment modifiability (i.e., the ability to modify physical objects in the VE) was restricted considering the low familiarity and experience of participants with the VR technologies. For example, the navigation path was fixed and predetermined. The anticipation of events factor (i.e., if users are able to predict what will happen next) was affected by the research design: the amount of information that users received prior to the VR visualization was severely reduced in order to reduce bias in their responses. For example, users waiting to wear the VR headset could not see the monitor screen showing the VE.

Sensory Factors (i.e., the extent and variety of sensory channels stimulated by the VE) were also limited because in this experiment only visual information was included. Although the Oculus Rift CV1 device includes speakers and hand controls that can be used to add auditory and kinesthetic stimulation, they were not considered as part of the scope of this experiment. The degree of movement perception (i.e. if the observer perceives self-movement through the VE) was low because the VE did not include a visible avatar. Remarkably, some participants moved their arms and hands in search of self-perception.

Choosing a fixed, predetermined navigation path with a slow motion pace proved to be effective to reduce dizziness, disorientation, and visual discomfort. However, some elderly participants chose to be seated, which was an unexpected request that created dissonance with the "walking" height and movement of the avatar. In this case, a stationary visualization scenario (e.g. pretending to be sitting on a park bench) would have given a more natural spatial perception.

Distraction Factors were affected by the nature of the experimental setup. Isolation (from their actual, physical environment) was not fully achieved, as the research design required the researcher to interact orally with the participants during the visualization process. Selective attention (on the VE stimuli) was limited not only by the researcher's questions but also by the general noise levels during the experiment and the fact that participants were aware that they were being recorded and photographed/filmed. Finally, interface awareness was also an issue as several participants felt the HMD unnatural and/or uncomfortable.

Regarding Realism Factors, information consistency with the objective world and the meaningfulness of the experience appeared to be the factors that contributed most to the sense of presence. All participants recognized the VE as a digital reproduction of their real neighborhood, identifying streets, buildings, and other landmarks with ease. In fact, two participants showed exceptional observation skills, detecting a light post in the VE that did not exactly match to the actual existing post. Remarkably, this inconsistency was not detected by the modelers nor by the architects and designers who reviewed the virtual model.

During the VR modeling phase, the urban designers requested to assign "neutral" pale color to 
the surrounding buildings as a way to highlight the park against the context. This is a common technique used in architectural models. However, this inconsistency was immediately detected and pointed out by most participants, causing the opposite effect to the one sought.

Overall, the combination of good results in Realism factors and limited results in Control and Distraction factors suggests that users achieved a high level of involvement in the virtual environment (VE), but an insufficient state of immersion.

In terms of the logistics and procedure on the field, the pilot can be considered satisfactory, although there are still several aspects that need to be improved in order to obtain an efficient process that can be massively applied for public projects. Some issues that need to be addressed are how to adjust the avatar height and measure inter-pupillary distance individually quickly in the VR model, and test standalone HMD equipment (as opposed as stationary) as a way to reduce setup time.

\section{CONCLUSION}

In general terms, this work shows that virtual reality technology is an effective tool for the visualization of architectural and urban projects in processes of participatory design, especially for people who are not familiar with traditional means of architectural representation.

The experimental results suggest that the use of virtual reality improves the level of spatial comprehension compared to traditional means, which, in turn, facilitates the generation of precise, relevant, and valuable comments to inform designers.

However, the study also shows that many issues need to be further investigated. First, it is necessary to study how to increase the number of sensory channels in the VEs to improve immersion and presence, including sound (ambient sound) and kinesthetic (ability to move) stimuli. Giving participants more control over the $\mathrm{VE}$, however, must be carefully evaluated, as it could pose a procedural and learning challenge for users not familiar with tradi- tional control devices (e.g. joysticks). Distraction factors derived from the general setup can be definitely addressed to increase isolation and selective attention. Second, in terms of model content, it is hypothesized that including people or animals realistically in the VE could avoid the "ghost town" effect and increase realism levels. Some symbolic elements light street names or existing landmarks could help people to recognize and navigate the VE. The impact of lighting and general environmental conditions (e.g., day/night, summer/winter) on spatial perception must also be evaluated. Third, the importance of the navigation experience design cannot be underestimated. The pilot project results suggest that a fixed, predetermined navigation path could introduce bias to the participants' comments (by indirectly selecting what they can or cannot see in the VE). It is necessary to study what are the advantages and disadvantages of using a free navigation experience, or as an alternative, to have several predetermined navigation paths offering different points of view of the VE. It also seems necessary to test stationary experience (e.g. based on stereograms), including specific experience for participants who prefer to be seated during the visualization.

In conclusion, this paper contributes to understanding how to utilize VR technologies in participatory design processes, and ultimately, to improve the quality of our buildings and cities.

\section{ACKNOWLEDGMENTS}

This research was supported by the Ministry of Housing and Urbanism of Chile and the Faculty of Architecture and Urbanism, University of Chile. We thank our colleagues Prof. Jorge Inzulza, Prof. Viviana Fernández and Prof. Hernán Elgueta for their valuable insight and expertise on participatory design, and Alejandro Flores, Simón Cárdenas, and Felipe Jerez for their help building the VR model and assisting on the field. Our gratitude to the Municipality of Pedro Aguirre Cerda and SERVIU Region Metropolitana for allowing us to work on this urban design project. 


\section{REFERENCES}

Abdelhameed, WA 2013, 'Virtual Reality Use in Architectural Design Studios', Procedia Computer Science, 25, pp. $220-230$

Angulo, A and Vásquez de Velasco, G 2013 'Immersive Simulation of Architectural Spatial Experiences', Proceedings of the XVII SiGraDi Conference, Valparaiso, Chile, pp. 495-499

Bakr, AF, El Sayad, ZT and Thomas, SMS 2018, 'Virtual reality as a tool for children's participation in kindergarten design process', Alexandria Engineering Journal, 57(4), pp. 3851-3861

Bruder, G, Steinicke, F, Valkov, D and Hinrichs, K 2010 'Immersive virtual studio for architectural exploration' Proceedings of the 2010 IEEE 3DUI Symposium, pp. 125-126

Bruno, F and Muzzupappa, M 2010, 'Product interface design: A participatory approach based on virtual reality', International Journal of Human-Computer Studies, 68(5), pp. 254-269

Crewe, K 2001, 'The Quality of Participatory Design', Journal of the American Planning Association, 67(4), pp. 437-455

Cámara, C 2012, 'Las iniciativas de participación ciudadana en el urbanismo.', Revista de Estudios Urbanos y Ciencias Sociales, 2(1), pp. 19-32

Drettakis, G, Roussou, M, Asselot, M, Reche, A, Olivier, A, Tsingos, N and Tecchia, F 2006, Participatory Design and Evaluation of a Real-World Virtual Environment for Architecture and Urban Planning, INRIA, Le Chesnay, France

Eisapour, M, Cao, S, Domenicucci, L and Boger, J 2018 'Participatory Design of a Virtual Reality Exercise for People with Mild Cognitive Impairment', 2018 Conference on Human Factors in Computing Systems, Montreal, Canada, pp. 1-9

Fernandez, V 20115, 'Promoviendo un diseño urbano participativo, experiencias desde la práctica y la docencia., in Inzulza, J, Zumelzu, A, Horn, A and Perez, L (eds) 20115, Diseño Urbano y sus aproximaciones desde la forma, el espacio yel lugar, MAVAL Chile, Santiago, pp. 216-228

Ghani, I, Rafi, A and Woods, P 2016 'Sense of place in immersive architectural virtual heritage environment' Proceeding of the 22nd International Conference on Virtual System Multimedia, pp. 1-8

Hayek, UW, Waltisberg, D, Philipp, N and Grêt-Regamey, A 2016, 'Exploring Issues of Immersive Virtual Landscapes for the Support of Participatory Spatial Planning Support', Journal of Digital Landscape Architec- ture, (1), pp. 100-108

Hermund, A and Klint, LS 2016 'Virtual and Physical Architectural Atmosphere', Proceedings on the 2016 ICALBE Conference, Kuala Lumpur, Malaysia

Kalisperis, LN, Muramoto, K, Balakrishnan, B, Nikolic, D and Zikic, N 2006 'Evaluating Relative Impact of Virtual Reality System Variables on Architectural Design Comprehension and Presence', Proceedings of the 24th eCAADe Conference

Kreutzberg, A 2014 'New Virtual Reality for Architectural Investigations', Proceedings of 35th eCAADe Conference, Newcastle upon Tyne, pp. 253-260

Kreutzberg, A 2015 'Conveying Architectural Form and Space with Virtual Reality', Proceedings of 33th eCAADe Conference, Vienna, Austria, pp. 117-124

Kreutzberg, A 2016 'High quality Virtual Reality for Architectural Exhibitions', Proceedings of 34th eCAADe Conference, Oulu, Finland, pp. 547-554

Kuliga, S, Thrash, T, Dalton, R and Hölscher, C 2015, 'Virtual reality as an empirical research tool - Exploring user experience in a real building and a corresponding virtual model', Computers, Environment and Urban Systems, 54, pp. 363-375

Luck, R 2007, 'Learning to talk to users in participatory design situations', Design Studies, 28(3), pp. 217-242

Milovanovic, J, Moreau, G, Siret, D and Miguet, F 2017 'Virtual and Augmented Reality in Architectural Design and Education,' Proceedings of the 17th CAAD Futures Conference, Istanbul, Turkey

MINVU, . 2010, Inventario de Metodologias de Participacion Ciudadana en el Desarrollo Urbano, MINVU, Santiago, Chile

Montiel, C and Loyola, M 2016 'Realidad Virtual como medio de representación de la experiencia espacial: su uso en el diseño participativo', Proceedings of the XX SIGraDi Conference, Buenos Aires, Argentina, pp. 590-594

Portman, M, Natapov, A and Fisher-Gewirtzman, D 2015, 'To go where no man has gone before: Virtual reality in architecture, landscape architecture and environmental planning', Computers, Environment and Urban Systems, 54, pp. 376-384

Thalen, J and der Voort, Mv 2012, 'Facilitating User Involvement in Product Design Through Virtual Reality', in Xinxing, T (eds) 2012, Virtual Reality - Human Computer Interaction, InTech, London

Witmer, BG and Singer, MJ 1998, 'Measuring Presence in Virtual Environments: A Presence Questionnaire', Presence: Teleoperators and Virtual Environments, 7(3), pp. 225-240 